"This team has been going out on
cleft trips for the last 13 years,
visiting many third world countries to
repair clefts for children who previously
would not have had treatment."

\title{
Hands-on training: working with a charity cleft team in Hyderabad
}

\begin{abstract}
Cleft lip and palate cases are somewhat academic for most people, with most modern clinicians having very little exposure at both undergraduate and postgraduate levels. Here, maxillofacial SHO Jiten Parmar gives an account of his experiences with a cleft team on a charity mission to Hyderabad, India.
\end{abstract}

My colleague Keith Farrell and I had worked together for six months and at the end of our contracts at North Manchester General Hospital, we both decided that we wanted to put our skills to good use with some charity work. Deciding what to do was more difficult than we had imagined, but both of us had worked in maxillofacial units with seniors who had been on cleft trips previously, and so we decided to chase up contacts and join a team in 2006 .

After much research and phoning around, Keith came up with a contact at Blackburn Royal Infirmary by the name of Dr George, Consultant Anaesthetist. Little did we know that what we were about to get involved in, the Northern Cleft Foundation, was actually run and organised by Dr George and his team. It turns out that this team has been going out on cleft trips for the last 13 years, visiting many third world countries with a team of surgeons to repair clefts for children who previously would not have had treatment. Each year, the team travels out, pays hospitals for their equipment and hospital time, and then perform as many cleft repairs as possible. The cost of all this is covered by money raised in the UK through charity fundraisers.

The time had come to set out on our trip. Having never met Dr George, I was slightly nervous to say the least about going out for ten days with a team that I had never met, and to perform surgery that I had never even seen before! I had tried to prepare for the experience by reading into the surgical

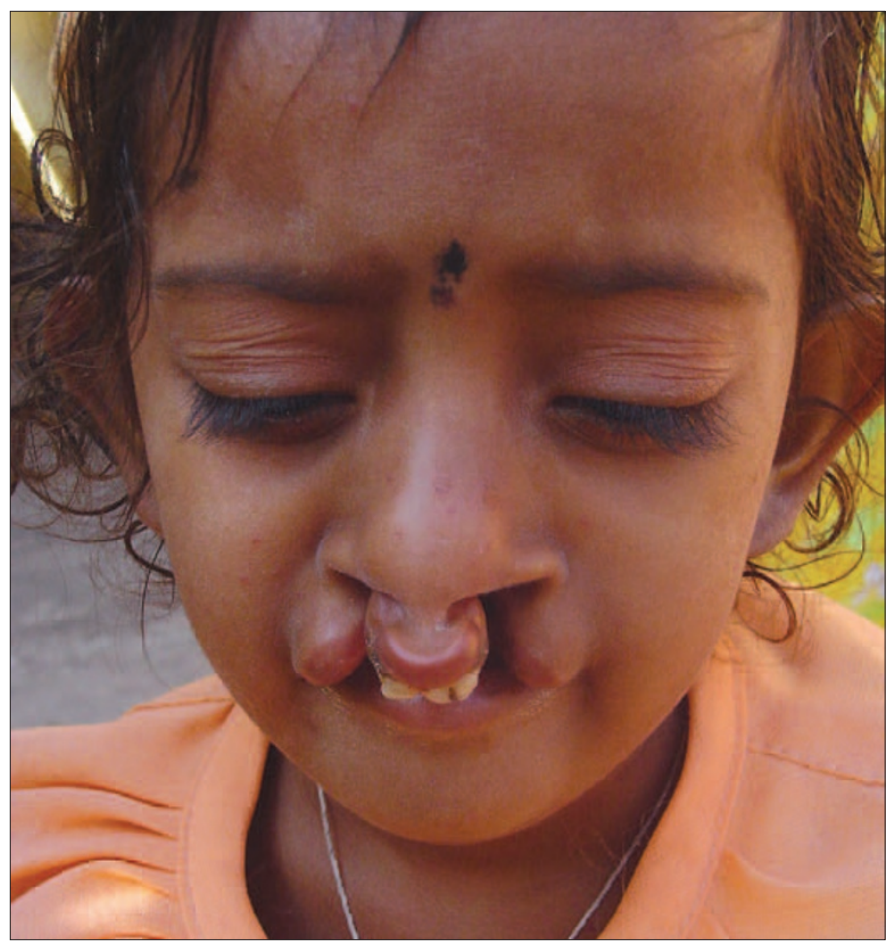

A child with bilateral cleft lip 


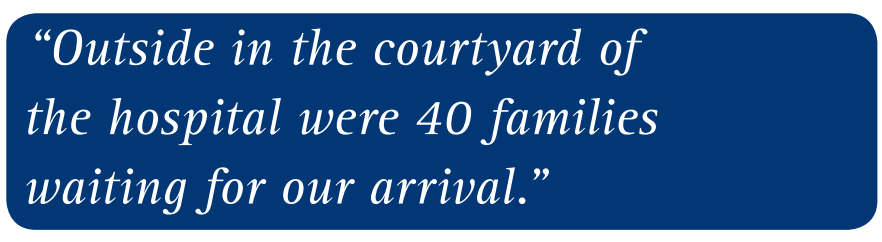

methods of repairing clefts, learning a little about Hyderabad and by speaking to my registrars in the hospital. All this preparation got me nowhere. The surgical reading left me confused and the Lonely Planet guide was of no use until I was actually in the city I was reading about! To say that the team of 26 were warm and welcoming was an understatement. Within minutes of meeting Dr George at the airport, we were promptly introduced to the rest of the team of four plastic surgeons, four anaesthetists, anaesthetics and recovery and theatre staff.

The long and daunting flight did not dampen our spirits, and after an early night by all in Hyderabad, we promptly set off the next morning to our home for the next ten days, the GSR Institute for Craniofacial Surgery, Hyderabad, India. We were welcomed there by the chief clinician, Professor Gosler Readdy. It did not take long for us to fathom the huge nature of the task we were undertaking. Outside in the courtyard of the hospital were 40 families waiting for our arrival. Seeing your first child with a cleft can be quite an overwhelming experience. I never realised how disfiguring a cleft could be, both aesthetically and functionally. It finally made sense to me that we were trying to reconstruct the obvious discrepancies in these children so that they could have the best chance in life to integrate and make a contribution to the community they lived in.

It did not take long to unpack all the medical equipment that we had brought over with us. We had everything from sutures to surgical trays, laryngoscopes and anaesthetic tubes. After a surgical and anaesthetic pre-assessment, we were ready to embark on something that was remarkable. I was impressed by the thoroughness of this experienced team. Parents were given informed consent for all treatment that was to be provided. Considering some of these people had never seen the city before (many parents had travelled from villages almost $300 \mathrm{~km}$ away), I completely understood the apprehension in many of their faces. The idea of their children being put to sleep truly scared them. These parents had been so accustomed to having their children grow up with a cleft (the ages of these children ranged from three months to 13 years) that it was completely understandable that they would be apprehensive about westerners coming in and changing the appearance of their beloved. A giant leap of faith was needed by all involved, especially as many of the children had poor medical histories.

One can never fully understand the intricacies involved with repairing a cleft until you actually see one being operated on. Most of the cases that we operated on were cleft lips. The other cases involved repairs of palatal clefts and one case of a skin revision following damage by a sebaceous cyst.

During our ten days in Hyderabad, Keith, Darryl (our ODP) and I managed to get out of the city to travel to a small town called Markapur, where we experienced a pre-assessment clinic. After an eight hour drive on some of the worst roads known to man, we arrived (sore) at this busy small town.

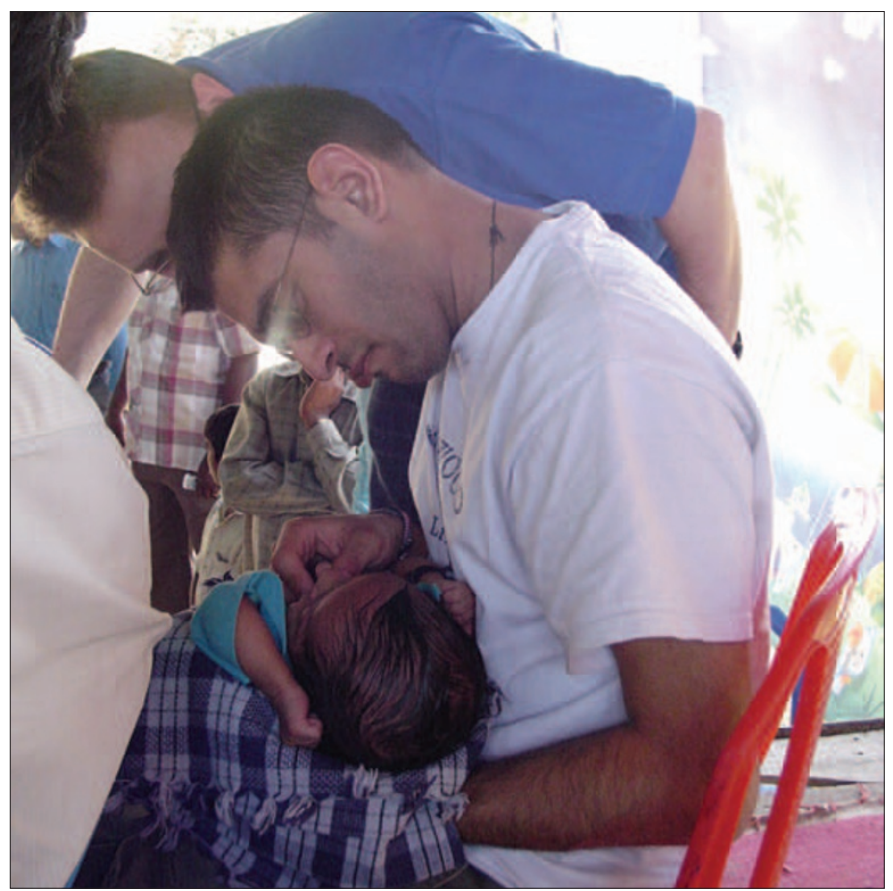

Team members during an assessment clinic

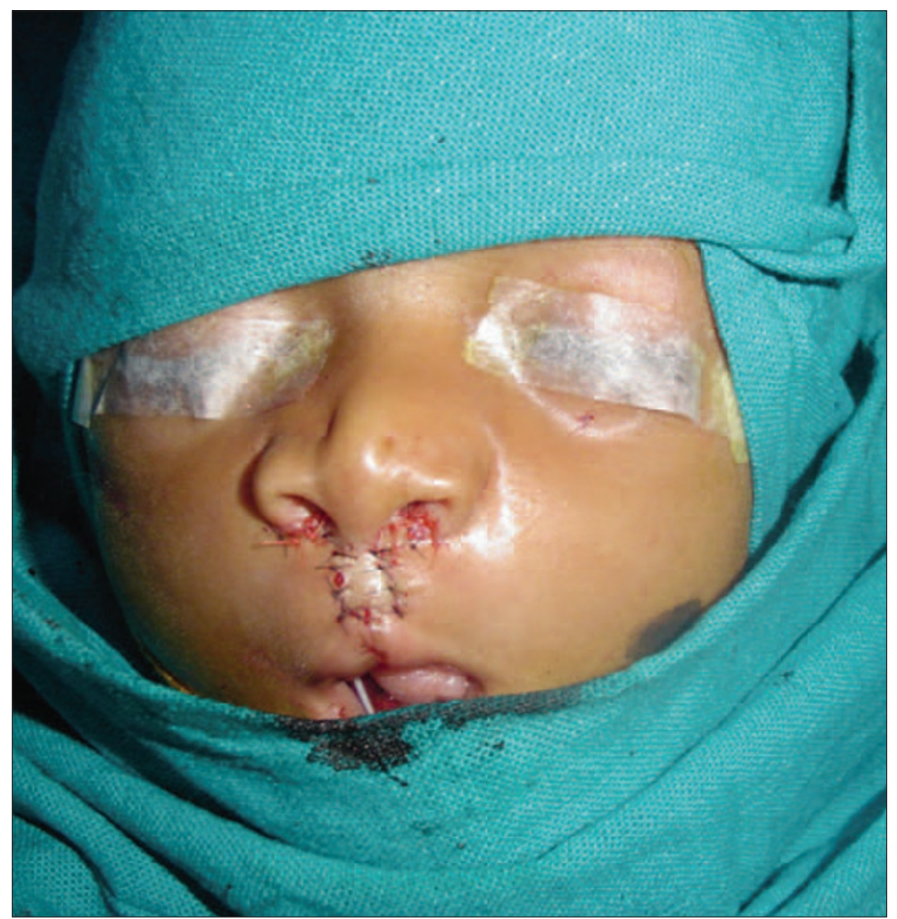

A young patient following cleft lip repair surgery 
We had been informed that villages and communities in the surrounding $100 \mathrm{~km}$ area had been given leaflets and pictures of facial discrepancies and told that if they thought that they had a patient that fitted the criteria, they should attend our pre-assessment clinic. One hundred and twelve people arrived hoping for treatment. To say I was overwhelmed was an understatement. We managed to see all sorts of patients with conditions such as facial haemangiomas, Apert syndrome, hemifacial microsomia and burns victims, as well as the cleft lips and palates that we were looking for. It was a bizarre experience having to reject a patient and tell them that we could not help them. Coming from an NHS background with a 'prompt' referral system, it was frustrating not having somewhere to send these patients for treatment. Nonetheless, 37 more patients were recruited for the hospital. The patients were given instructions to wait in the town in 10 days time, with their own food, for the hospital bus that would transport them to the hospital $300 \mathrm{~km}$ away. The next batch of operations that would happen after we left India was ready for Professor Gosler Readdy.

After a two hour pre-assessment, we were back on the road again to return to Hyderabad. It was only then that we were fully informed of the dangers of this route, where many individuals had been ambushed by a communist upheaval in the area. After firmly locking our doors and piling all our faith into the deity Ganesh on the dashboard, we powered back through jungle and mountain roads to the city.

Eighty-six clefts were repaired by the team in the ten days that were there - a remarkable feat that was only made possible by the underlying team effort and persistence of this British team of 26 individuals. The surgical and anaesthetic training that the Senior House Officers (SHOs) received was second to none. I could never have imagined that I would be working so closely with consultants who had made it their life's passion to provide safe and effective treatment for children in so much need. Dr George told me on the trip that he was once visited by a young girl after her operation. She explained to the team there at the time that she was grateful for the opportunity she had received to possibly get a job, and one day even get married. Dr George felt a lump in his throat when he heard this the first time round. Hearing the story years later did the same for me.

I really miss India. I miss treating children who truly deserve the best in life. It is rare to find children who have so little fear and no concept of pain, who deserve a chance in life to 'fit in' and become members of the community. I hope to return to India to do more cleft charity work. In the meantime, it's back to the drawing board to raise some money for the next trip out next year. Considering that each case we treated cost us on average $€ 120$, it does not take a genius to understand the amount of money required to buy essential equipment and to pay for operating time in these Indian hospitals. It is hoped that by doubling the number of operations that the Indian teams can perform in a week, we have played our part in reducing the very long waiting lists that the GSR institute faces.

For any SHO interested in doing some charity work abroad, and wanting to improve their knowledge in a surgical field that he or she may have little exposure to, I would heartily recommend going out with a charity cleft team. I feel lucky that I was blessed to travel and work with what can only be described the nicest and most professional and welcoming team I have ever had the pleasure of being involved with. Many thanks to Dr George at Blackburn Royal Infirmary, Dr Venkataraman and Dr Avazaso at Wigan General Hospital, and Mrs Carolyn Reid, Mr Peter Hodgkinson and Dr Tremlett from Newcastle General Hospital, for taking us under their wings and providing me with the most rewarding ten days I have ever experienced.

\section{Jiten Parmar}

Senior House Officer, Maxillofacial Surgery,

North Manchester General Hospital

jitendparmar@hotmail.com

For more information about the Northern Cleft Foundation, please contact Dr George at Blackburn Royal Infirmaryat arangeet@yahoo.com

DOI: $10.1038 / b d j .2007 .196$ 